\title{
Children's right to be hostile in research: emotions and agency through psychodynamic lens
}

\begin{abstract}
This paper explores children's hostility towards adult researchers and shows how individual acts of hostility might be linked to wider contexts in children's lives and to their relationships with others. Drawing on ethnographic research with children in Slovakia and psychodynamic theories of Alfred Adler and Anna Freud, the paper argues for hostility to be seen as a legitimate form of children's political agency and one which might require escape from adult logics and interpretations. It suggests that children's hostility towards the researcher should be seen as a right before it is considered a problem, and it should not on its own exclude children from participation in research. Tracing the emotional dynamics of research-participant encounters and their links to other social relationships, personal histories and emotional materials, the paper suggests that recognising children's agency as too elusive for adult interpretations might facilitate new forms of research participation, one which would not rest as heavily on the adult conceptions of childhood.
\end{abstract}

\section{Introduction}

"The first week of the fieldwork was about getting to know children whom I would be meeting during the afternoon community work shifts. On the second day, a colleague introduced me to Lina, a seven-year old girl. As I told her my name, Lina looked me in the eye and said: 'Your mum is a whore'". (Research Diary, October 2008)

This paper seeks to reframe children's hostility from a research failure (ethical, methodological, personal) into an opportunity to better understand children's lives, enhance the notion of research participation and reflect on partnerships beyond a narrow researcher-participant framing. The argument follows my relationship with Lina, a young participant in an ethnographic project located in a community youth work setting in Slovakia (Author Date). It tracks expressions of Lina's ongoing and sometimes violent hostility which I failed to understand at first and which I thought had signalled my failure as a researcher and put my research in jeopardy. The story then departs from the perception of Lina's hostility as a failure, embraces Lina's right to be hostile, and proposes an affirmative approach to hostility based on psychodynamic and psychoanalytic theories and a collaborative conception of fieldwork beyond research.

The paper draws on theorisations of children's political agency, children's emotional geographies, emotions in research participation, a 'sense of failure' and psychodynamic theory, and it offers a three-fold contribution to the literature on research with children. First, by deploying Alfred Adler's and Anna Freud's psychodynamic perspectives on emotions, it scrutinises the immediacy of the researcher-participant dynamics within the contexts of children's ontological security, wider geographies of family life and personal relationships, and the formative constitution of their political agency. Second, it links the psychodynamic concepts of 'striving for significance and superiority' and 'displacement' to methodological opportunities to explore children's lives through a collaborative approach that draws on child practitioners' expertise and interventions, thus reframing and extending the notion of research participation beyond the space of research. Third, and ultimately, the paper reconciles children's right to be hostile and antagonistic with their right to participate in research by locating children's hostility within the formation of their agency. 


\section{Children's hostility in research: emotions, agency and the sense of failure}

Debates on children's participation rights in research have followed the social scientific shift since the 1990s towards participatory and collaborative modes of engagement, acknowledging the importance of children's agency and power in adult-child relationships (Powell and Smith 2009). The notion of children's participation rights rests on the prospect of children as social actors with views, competences and the right to be heard through appropriate means (Einarsdóttir 2007). However, there is also a growing recognition that rights-based approaches to children's participation in research need to be entrenched in children's everyday circumstances rather than universalist assumptions about child subjectivities and adult-child relationships (Nolas 2011). This requires discerning how these circumstances are shaped both by the wider social settings of children's lives and by children's individual personhoods (Fay 2018), and it inevitably leads to situated and sometimes conflicting notions of agency, vulnerability and inclusion (Pells 2012).

The discourses on children's participation rights tie children's involvement in research to the legitimacy of children's voice and expression. In order for children's views, experiences and voices to be considered in the knowledge production, they need to be articulated in a manner that fits within the epistemological frameworks of research, ultimately put in place by adult researchers. Failing to articulate in a legitimate manner, one that would transform children's voices and expressions into valid empirical material, inevitably leads to exclusion from the process of knowledge production (Poretti 2019).

Kirsi Kallio (2012) presents a detailed critique of the emphasis on hearing the child's voice as an underpinning principle of the United Nations' Convention on the Rights of the Child (UNCRC) but also behind participatory processes involving children more general, including social research. Kallio's claim is twofold. First, she argues that children's voices are appreciated as such only if they conform with appropriate discursive notions of childhood. Second, she points that the adult design and initiation of participatory processes often lead to dismissal or masking of certain children's knowledges and experiences. Kallio explicates that children's voices are filtered in participatory processes by recruiting certain children for the production of certain kind of information, by subjugating some children's voices by endorsing those who engage in participatory activities more effectively, and by governance and regulation within the participatory processes themselves. These often emerge from the lack of attentiveness to difference and power relations among children themselves, as perspectives of children who struggle or refuse to engage with the expectations of participatory approaches become marginalised compared to those who conform with adult expectations on children's participation.

The right to be involved in research is not just a matter of discursive legitimacy, however. Children do not articulate themselves only through their voice but also through other forms of action.

Children's embodied practices in interpersonal relationships have the potential to inform knowledge production as much as children's words, images or other forms of representation (Proctor 2013). Yet, in order to be involved in research production, children's practices still need to meet certain expectations. There is an increasing emphasis on the importance of emotional dynamics in research with children, but certain emotions tend to remain overlooked (Hadfield-Hill and Horton 2014), while others are delegitimised and seen as problematic. With much of the recent shift in research with children steering towards the ethical stance of care, support and de-hierarchisation (Skovdal and Evans 2017), and with the methodological importance of dialogue with children (Birch et al. 2017, Powell et al. 2019), hostility within the researcher-participant dynamics in particular tends to be seen as an obstacle to participation, because children's antagonism to the researcher contradicts the idea of collaborative partnership. In addition, the significance of power relationships between 
adults and children in general (Kina 2012) leads to the perception of children's hostility as a sign of children's resistance to adult power and a signal of the adult researcher's personal or ethical failure in the relationship building. Even in the wider literature on hostility and violence in children's lives, hostility experienced by children receives more thorough attention (Harker et al. 2017) and little consideration is given to children's hostility to adults.

If children are to be considered as social subjects on their own, their hostility to adults should not be seen reductively as a defiant response to adults, but rather as an affirmative form of children's own political agency. On the example of scream, Rachel Rosen (2015) shows that that children's practices that adults might experience as disturbing, unpleasant, alerting or even antagonistic 'matter[] to those who produce[] them' (p.49) in a way that may not be quite meaningful to the adult observer. Rosen advocates against overinterpretations of the meaning behind such actions by those who witness them and instead points out to their significance as 'an important political expression, even in the limited but important sense of mattering and affecting those who produce and sustain' it (ibid., italics added). Refraining from the search for interpretations of meanings behind children's actions that would fully fit within the adult logic is crucial for challenging the adult-child framing where 'children are often apprehended in ways that tend to rob them of any spontaneous political agency that cannot be traced back to what is readily known to be politically relevant in adult terms' (Häkli and Kallio 2014, p.182)

A major contemporary perspective on children's political practices suggests that they unfold through everyday embodied tactics (Kallio and Häkli 2011; Elwood and Mitchell 2012; Karlsson 2018). This is, as Kallio (2007) explains, because 'children's politics is based on the autonomy they hold over their bodies... [and while they] do not have autonomous positions at other political scales, the right and ability to control and command one's own body belongs to them' (p.126). Contrasting the children's embodied agency with adult regulatory and disciplining techniques that rest on the primacy of discursive logics, Mary Thomas (2019) then argues that adult institutions subjugate children largely by discussing with children their bodily agencies 'ad nauseum' while at the same time curtailing those very agencies and delaying and restricting children's spontaneous bodily expressions and desires. Even though the academic literature of the last decade highlighted the significance of children's embodied practices, a romanticised notion of children's political agency still prevails in those depictions that emphasises children's caring traits (Bartos 2012; Blazek et al. 2015) and their resistance against wider adult structures (Aufseeser 2018; Karlsson 2018) - in other words, aspects that correlate with adult idealisations of children's subjectivities. Children's hostility towards individuals and particularly individual adult researchers is not taken seriously as such and tends to get dismissed as the researcher's failure, not as the child's right and competence. Hostility is arbitrated from the moral grounds of adult apologetic introspection ("where did I do wrong?"), not the ontological grounds of children as emotional agents situated in socio-emotional relationships from which the hostile acts emerge.

One approach presented with the potential to disrupt the adult-centric comprehension of children's acts and to critically interrogate the conception of age and generational differences and their significance is by focusing on the contextual emotional experiences of age (Kallio and Thomas 2019). Hanne Warming (2019) argues that 'age does not determine which generational positioning a person is ascribed and identifies with' as 'intergenerational relations [are] constructed through affective encounter' (p.2). Kirsi Kallio and Mary Thomas (2019) then suggest that approaching age relations as constituted via such emotional dynamics opens allows to identify 'situations where social routines are disturbed', prevailing norms 'challenged' and new 'ways to perform individual and collective identities, and other active ways of affectively relating to other people' (p.3). It is worth noting that a 
focus on material agency, interembodiment and emotional attachments and dynamics extends the scope of childhood research also towards younger children and infants, a group that sociologists and geographers have been more hesitant to focus on (Holt 2013, 2017).

It is with such a logic, away from preconceived notions of model relations between adults and children and with attention to the emotional dynamics of embodied interpersonal encounter, that I wish to approach the notion of children's hostility. Children's hostility to researchers should not be automatically reduced to an instance of researcher's failure before its significance in children's agency is further scrutinised. A 'sense of failure' has a strong presence in the methodological literature on research with children, and as John Horton (2008) shows, it is closely linked to preconceived notions of model relationships and practices between adults and children. Research participation can entail a major emotional burden for both the adult researcher and child participant (Kina 2012; Bosco and Joassart-Marceli 2015), amplified if failure is perceived by either side (Klocker 2015). Of course, I do not suggest that children's hostility should be overlooked - quite the opposite, because it can be (and often is) a sign of emotional trauma where a careful response, likely involving other competent professionals or adult stakeholders is warranted (van Blerk and van Blerk 2015). Nor do I suggest that adult researchers cannot be responsible for children's hostility and they should not carefully reflect on their actions in relationships with children (cf. Pinkney 2011). However, the emergence of hostile acts and their significance should not be automatically reduced to an individual adult researcher's failure just as children's actions should not be diminished to responses to adult agency. Through the story of Lina, the rest of the paper will exemplify the disentanglement of my (the researcher's) introspective sense of failure from wider dynamics in which hostility takes place.

My argument is thus twofold: 1) children's hostility towards the researcher should be seen as a right, not a problem, and it should not exclude children from participation in research, unless that hostility is not indeed an expression of not wanting to participate (noting that children might not wish to participate and yet fail to express any hostility, for instance because of fear); 2) children's hostility should be seen as a legitimate form of political agency, but one that needs to be contextualised within wider social entanglements of children's lives, not reduced to a researcher's failure in the individual relationship. Together, this argument seeks to reconcile children's right to be hostile with their right to participate in research, and to encourage research tactics possible to build from such a juxtaposition.

In the following sections, I offer an approach that develops and exemplifies this argument further, drawing on the psychodynamic frameworks of Alfred Adler and Anna Freud. The choice of psychodynamic theory is partly serendipitous. The next section explains how an Adlerian perspective was suggested by one of my non-academic collaborators and how this was then enacted in my dayto-day work with Lina. However, following the point made by Mary Thomas (2014), I also see the value of psychodynamic theories in providing a counterpoint to the conceptions of 'sociological child' centred on autonomy, knowledgeability and competence. Rather than either dismissing the limits of children's agency or sliding back to developmental discourses of children as incomplete adults, (some) psychodynamic theories have the potential to break down the adult discourse and subjectivity by destabilising the very notion of 'informed adult agents' (Thomas 2014, p.201). This aspiration is of course shared with other frameworks, and some of which have perhaps become more popular in recent times, such as non-representational theories (Kraftl 2013), new materialism (Rautio 2013) or object-oriented ontologies (Kraftl 2020). In the final section of the paper, I briefly discuss how psychodynamic theory share some perspective with these frameworks (just as it does with the sociological study of childhood) but how it differs. 
Finally, before discussing the story of Lina, I need to say a few more words about the methodology and the research behind this paper (with more details on the project in Author Date, and a specific account of the detached youth work approach in Author Date). It is based on an ethnographic project investigating the formation of children's agency that I undertook between 2008 and 2011 in a marginalised neighbourhood of the Slovak capital, Bratislava. I volunteered with a local community organisation as a youth worker, primarily spending time in the streets of the neighbourhood as a detached youth worker with children aged between 5 and 14. The agreement with the organisation was that my youth worker duties would be always fully prioritised over the research agenda and I would conduct activities outside the youth worker role, thus limiting the research element to experiential accounts of being with children on a day-to-day basis. The nature of the contact depended fully on the children. The street was a place where the children made the rules and I had no formal authority nor was I expected to assert any (e.g. I would not be expected to prevent children from fighting, only suggest alternative ways of addressing conflicts). Although I sought to explain my research identity as I was introduced to new children, this rarely received much attention and children's recognition of myself was primarily via the role of youth worker. As the question of consent or refusal to engage with me is crucial to the reading of Lina's story, it must be said that this was not as much about participating in my research but rather about engaging in a relationship where my professional role was that of a youth worker.

\section{Shifting the hostility between us beyond us: an Adlerian approach to power perceptions and relationships}

\section{Research with a hostile child}

The first encounter with Lina, presented at the beginning of the paper, was shocking but not unique. On numerous occasions when I met Lina over the next few weeks, she attacked me verbally or physically (kicking, spitting, throwing stones) with what I saw as no reason. All this alternated with much more amicable moments when Lina and I spent time with other children or just on our own as I embarked on my role as a detached youth worker in the neighbourhood.

I struggled to understand these acts, and I struggled to develop a response. Three elements coalesced in my reaction. First, I thought that I must have done something wrong, failed in my role as a researcher and youth worker and in establishing a relationship based on respect and trust. Even though violence was common in children's practices in the neighbourhood, I thought that Lina would not have attacked $m e$ if she had no reason. However, despite replaying the instances of her hostility carefully and repeatedly, I could not identify the moment(s) that would have provoked Lina and accounted for her violence. Second, with my research exploring children's agency and practices in a community setting, I was hesitant to interfere in Lina's actions, even if they were unpleasant and hurtful, and strived to consider them as an object of inquiry. Rather than seeing Lina's hostility as a problem to address, I was focused on understanding it with a researcher's hat on, which, at the time, meant downplaying the significance of my own feelings about the situation. Third, Lina's actions began causing difficulties to my research, not just because of the emotional aspect of the hostility, but because of the effect it had on other children and my relationships with them. Some children found inspiration in Lina and amused themselves in attacking me too, while others were determined to defend me, leading to a couple of unpleasant incidents between the two groups.

After a month, I decided to address Lina's hostility and asked a senior youth work colleague for a supervision meeting. She asked me to present my records of encounters with Lina (which I kept as 
part of the research diary) and offered an analysis which interpreted Lina's hostility as acts related to power and attention. The diary showed Lina being hostile in moments when she felt uncertain about the attention received from me and others. For instance, hostility often happened the end of youth work shifts when it was clear that I was about to leave. My very first experience with Lina could be also interpreted through the lens of attention, as my arrival to the neighbourhood attracted group of Lina's friends who would have otherwise focused on playing with Lina. The diary showed many of Lina's kind moments in situations when she needed something - to lend a play equipment, help with homework, or just give company when none of her friends were out in the street - and earlier in the afternoon shifts when it was clear I would not be leaving any time soon.

My supervisor advised me to talk to Lina and present three messages:

1) that I intended to be her "friend", my "friendship" was unconditional and she could expect me to act in certain ways (listen to her, play with her, help with homework...) no matter what;

2) that all of this had a certain frame and limitations in terms of the amount of time I would spend in the neighbourhood during my shifts, and that I would offer it in equal amounts to other children, but that this frame would not take away from what she could expect from me;

3) that I felt hurt by her actions and did not understand them, and that I was sorry if she felt angry at me and wished to be on better terms in the future.

To my surprise I had never relayed either of these perhaps obvious messages to Lina before. I never fought back or attempted to assert my adult authority to challenge her hostility (I tended to let her do as she felt), but I had never attempted to reassure her of our relationship and of my role as a youth worker or expressed how I actually felt about her actions. Following the supervision, I spoke to Lina at the next opportunity and although she did not say a word or even looked at me at that time, she did not interrupt me either. I did not experience any signs of such open hostility from her after that day. On the contrary, Lina came to my swift defence on a couple of occasions when other children attempted to replicate her behaviour towards me.

\section{Adlerian interpretation: striving for significance and superiority}

As I found during our subsequent conversations, my supervisor's explanation of Lina's behaviour and her advice on my response were informed by the Adlerian psychodynamic theory. Alfred Adler was an Austrian psychologist, a close colleague of Sigmund Freud in the earliest years of the psychoanalytic movement and the second president of the Vienna Psychoanalytic Society (after Freud) between 1910 and 1911, when his departure from the Society marked the first significant split in the psychoanalytic community. Adler became a foundational figure in the Individual Psychology framework, which shifted from the primary focus of psychoanalysis on unconscious processes towards the importance of social factors, and influenced fields ranging from psychotherapy to social pedagogy.

Adler's theory is teleological. He moved away from the psychoanalytic explanation of human action as driven by unconscious drives and asserted that behaviour is always goal oriented, even if those goals are not necessarily understood by the actors themselves (Adler 1956a, 2009). A key aspect of the goal-oriented behaviour is the notion of striving for significance and superiority. Critically, significance and superiority in the Adlerian sense do not have to have an external object (being superior over someone else or significant to someone else), and they can be understood fully within the confines of self-perception, as shifts from a self-perceived "lower" position to a "higher" one 
(Dreikurs 1967). Reconciling with the more socially oriented literature in childhood studies, the striving for the sense of superiority can thus be rephrased as a desire for experienced empowerment, and Adler put this in contrast with the craving for power as a vehicle towards superiority over others. In one of his most overtly political writings, Adler indeed vehemently contested the conception of power as a mode of dominance, arguing that ' $[w]$ hoever desires the human community must renounce the striving for power over others' (Adler 2004/1928, p.85). The striving for superiority and significance takes place across all social relationships people have in their lives and the experience of one relationship inevitably impacts on the perception and actions in another one, just as the sense of empowerment and marginalisation may travel across different relationships and social positionings. Adler and his colleagues and followers paid much attention specifically to children's violent and disruptive practices. For Adler, these need to be seen as an instance in which the child experiences a feeling of inferiority (i.e. disempowerment or marginalisation) and develops a "goal which no longer guarantees only reassurance, security and equality, but which develops a striving for power aimed at superiority over the environment" (Adler 1956b, p.384, italics added).

Adler's theories have been particularly influential in the field of child psychology and pedagogy. Rudolf Dreikurs (1957; also Dreikurs and Solz 1987) suggested that children's display of hostile emotions is a way of challenging and maintaining control in the relationships with adults. In Dreikurs's view, children's disruptive practices has generally four goals: attention (to increase the sense of significance via the adult's recognition), power (to increase the sense of superiority via the specific relationship with the adult), revenge (as a manifested act of rebalancing and sustenance of power) and display of inadequacy (to receive attention and move from the perceived inferior /overlooked/ status). Lina's acts indeed displayed these four elements - it was impossible to overlook her acts, many of which would be deemed inadequate/inappropriate for a seven-year old girl, and they all without any doubt affected me, my experience and actions.

An Adlerian interpretation of Lina's behaviour as a strive for attention and power matched the records in my diary, and it helped inform my response to Lina's hostility that put a halt to it by declaring to Lina that she can claim a "superior" position of a respected and attended partner in our relationship without violence. What Adler termed as a 'sense of superiority', and which can be translated into the more contemporary social-scientific debates as a 'sense of empowerment', could thus be attained as an enhanced experience of equality in the relationship, transforming the embodied manifestations of Lina's agency. I did not ascribe an interpretation to the 'reasons' behind Lina's hostility and I never asked for those reasons; instead, I sought to reframe the affective dynamics of our relationship and encounter. However, I do not simply intend to suggest that Adler's framework should be adopted for interpreting and responding to children's hostility. Rather, I take it to formulate a broader point that children's hostility to an individual researcher might manifest more than just the individual relationship of the two. Both the adult researcher and the child participant enter the relationship with pre-existing life experiences, emotional dynamics and patterns of responsive behaviour that both shape and are shaped by their everyday experience. In addition, the Adlerian framework suggests that while children's hostility needs to be seen as a question of power and power struggle, the issue is not necessarily just how to challenge (or not) these power dynamics (Gallagher 2008), but also about focusing on how children themselves perceive and experience these power relationships. In the Adlerian framework, a key to understanding these questions is to explore immediate social relationships, both past and present, as well as children's subjective perceptions of these relationships (Dreikurs 1997). Linking to the contemporary literature on children's political agency discussed in the previous section, this further stands for exploring how children's agency emerges from these relationships and might materialise in the fleeting interpersonal encounters with particular emotional elements. 
From an Adlerian perspective, Lina's hostile practices were not necessarily a manifestation of her feelings towards me, which would have explained its very rapid and seemingly random occurrence. Rather, the theory suggests that those actions were related to other facets of Lina's life, and it raises a challenge to understand this "elsewhere" better. While I felt that our relationship changed as Lina's perception of it shifted and her goals were reframed, the underlying dynamics of her hostility were yet to be understood better.

\section{Hostility as a defence mechanism: displacement of feelings}

One piece of knowledge I came to recognise as important was that, aside from Lina's father, I was at the time the only male adult in Lina's everyday life. Lina never attended a nursery and had only just enrolled in a primary school where all her teachers were female; all other youth workers she met were female; her family, including two older sisters and two younger siblings, had little mobility outside the neighbourhood and very few regular social contacts. Through working also with Lina's siblings, I came to understand more about Lina's family dynamics. Most of the caring responsibility fell on her mother. Lina's father spent time away from the house, at work or elsewhere, and while the children often expressed their fondness of the father, he was also known for his drinking and sometimes volatile behaviour. Lina rarely mentioned her father, yet some of her siblings did, voicing affection and liking about the moments spent together, but also worries about his strict character and reflections of his limited and somewhat unreliable presence in their everyday lives. These recognitions, along with the fact that Lina did not manifest any such hostile behaviour (or at least with such regularity and at such a scale) to other female colleagues, made me question the role of gender in our relationship and the possibility of a link between her hostility to me, her relationship with her father, and his role in her life. I wondered whether her actions to me could have been in some way reflections of her feelings towards her father and towards her relationship with him.

Such an interpretation resonates with the psychoanalytic concept of defence mechanisms, specifically with the idea of displacement. Defence mechanisms, a framework originated in earlier Sigmund Freud's writings (Freud 1955/1909) but formulated and developed in most detail by Anna Freud (Freud 1992/1936), are unconscious ${ }^{1}$ responses to unpleasant or threatening impulses and emotions, protecting the Ego, the largely conscious and "coherent organisation of mental processes" (Freud 1991/1923, p.443). As Clark (1998) highlights, they are not deliberate choices. They operate as unconscious processings, subjective distortions and automatic responses to intolerable feelings and internal conflicts. Defence mechanisms protect the subjective experience of the Ego against intolerable desires, unbearable fears, unacceptable emotions or impulses (Fredrickson 1999).

Displacement is an example of defence mechanisms. Displacement unfolds either as an unconscious redirection of hostile feelings from an unsafe object (e.g. one who can punish the subject for the negative feelings, or one where the acceptance of hostility is unbearable, such as hating/being angry at a parent or another close person) to a safe one (one where the actions will not have such repercussions or will not threaten the perception of security in an important relationship), or it acts as a postponement of those feelings (Fenichel 1996/1946). This might suggest that where Lina felt angry or unhappy about her father, she displaced that hostility onto me, acting on the emotions in a

\footnotetext{
${ }^{1}$ The idea of defence mechanisms resonates also in Adler's writings (e.g. Adler 1931/1958), but as he departs from the focus on the unconscious, he conceptualises them as automatised practices that are just not fully understood by the actors themselves.
} 
violent action without the risk of belligerent response from her father and without challenging her the sense of familial security in the perception of a strong relationship with the father.

Thinking through the idea of displacement had two implications. First, it helped me question and subsequently gather additional insights into Lina's social geographies. As an ethnographer, I would not have probably paid much attention to Lina's father's role in her life as she rarely mentioned him and did not wish to talk about him. Approaching Lina's hostility to me as a displacement of her feelings towards the father highlighted his importance in her life and the intricacy of her attachment to him. Investigating that I became an object of Lina's hostility as the other only adult male in her everyday life then shed more light on Lina's social context, including her and her family's sociospatial isolation, local stigmatisation and racial marginalisation (as a girl of the Roma background). My methodology granted me only limited initial insights into Lina's familial geographies (cf. Hall 2011), but a psychoanalytic approach generated questions and interpretations which I was able to explore through additional engagement with Lina, her siblings and friends, as well as the community practitioners working with Lina.

Second, and more important for my general point about approaching children's hostility in research, the psychoanalytic approach offered an insight into possible ways of working with this hostility through a focus on the actual, congruent relationship with Lina. In her earlier polemics with the psychoanalyst Melanie Klein, Anna Freud (1974/1927) argued that unlike the Ego and Id, the Superego - the internalised and largely unconscious system of understanding what is right and wrong, acceptable and unacceptable - is not an innate element of the psyche and children develop it only gradually. Young children's (conscious and unconscious) understanding of what is right and wrong thus depends on external validation. Framing particular acts of young children as inappropriate (e.g. hostile) is an adult attribution, not necessarily an obvious children's conceptualisation, and children's understanding of those acts as right or wrong, appropriate or inappropriate, or friendly and hostile, inevitably emerges from within their relationships and interactions with adults, particularly in play. This strongly resonates with the literature presented in the previous section which comments on the dismissal of children's embodied agency if it does not fit with the existing discursive frame generated by adults. Although play has a prominent place in research methodologies with children, Anna Freud's psychoanalytic perspective does not approach play as a projective technique to generate data into children's views that substitutes spoken language (e.g. Pimlott-Wilson 2011), but rather as a tool for relationship making and embodied interactions.

Like other psychoanalysts, Anna Freud (1951) regarded the clinical setting as crucial for understanding children and their development, but unlike many of her colleagues, she insisted that the psychoanalytic interpretation process can also happen in natural observation. A key element of the psychoanalytic technique is transference, the unconscious redirection of feelings from a realworld object onto the psychoanalyst. Transference was at the core of Anna Freud's approach, but unlike with other child psychoanalysts such as Melanie Klein, who insisted on a purely clinical setting of the psychoanalytic process, Freud highlighted the prospects of a dual relationship in which the adult assumes the position of both an object of transference (to which the child redirects their feelings from a real object) and a new developmental object (the real person in a real relationship) (Freud 2018/1965). Adopting psychoanalytic methodology in a non-clinical setting thus requires both to adopt the psychoanalytic interpretative framework in which the adult can be an object of transference, and to accept the role of a real person in children's relationships. At the heart of this process, and as an ultimate bridge between the two positions, is the focus on children's emotional experience of this relationship, both real and transferential (Bonaninio 2007). 
Whereas the clinical setting of psychoanalysis might expect the interpretation of unconscious dynamics and conflict to be voiced and offered to the client (Freud 1958/1914), this might not be possible or appropriate in a non-clinical setting of pedagogic or research relationships with the children. This is where Anna Freud departs from the work of her father in a major way, as she does not necessarily demand to voice and interpret transference immediately. Instead, she accommodates that interpretation into the real relationship with the child in play (Couch 1995). For social research settings, this creates the possibility of working with materials and ideas that remain unspoken by the adult researcher and child participant, but which nonetheless guide their relationships and everyday practices and later inform the research process (Blazek 2013). With Lina, a break in our relationship happened when we acknowledged its existence and genuineness, instead of attending to it through the prism of modelled positionalities in which I approached Lina as a child research participant and she approached me as an object of transference.

In sum, approaching Lina's hostility through the psychoanalytic framework of defence mechanisms helped me identify new lines of inquiry and formulate an interpretation of Lina's hostility which shed more light not just on our relationships, but also on Lina's wider social geographies. It also helped me identify aspects of our relationship that were congruent and those where Lina's emotions might have been an outcome of the displacement process and where I failed to consider Lina as a real partner in a real relationship.

\section{Conclusions: psychodynamic perspectives on children's right to be hostile}

Earlier in this paper, I referred to Mary Thomas's (2014) claim for the potential of psychoanalysis (and psychodynamic theory more widely) to step away from child-centrism present in contemporary social studies of childhood and yet avoid slipping back to the adult-centric assumptions about developmental stages (also Kallio and Thomas 2019). I also mentioned psychodynamic approaches next to frameworks such as non-representational theory and suggested that while they may share the intention to problematise the limits of meanings and representation that can be categorically delivered in research with children, they differ in some fundamental ways. This is therefore a good place to reflect on the psychodynamic perspective (at least as I built on it in this paper via Adler's and Freud's work), and to trace how it can both spring from and add to the broader social scientific literature on children's participation, emotions and agency. I will then return to the notion of children's right to be hostile (in research) to conclude the paper.

Where psychodynamic interpretations differ from much social research and find themselves perhaps more aligned to non-representational theories is their (partially) speculative nature and limits to which they can rely on empirical 'evidence'. The key reason for is that the unconscious, as the centre of psychoanalytic inquiry, is never directly accessible to observation. However, as I sought to show throughout the presentation of my story with Lina, this speculativeness does not afford the researcher impunity in drawing interpretations about children, and three other elements are crucial. First, if integrated with ethnographic research, the interpretation emerges from affective encounters and co-experienced moments, rather than from representations of children's lives through voice or similar. This opens up the potential of psychodynamic theories to support perspectives on children's agency and participation that are critical of the centrality of children's voices and of the neglect to children's emotional and embodied registers. Second, I illustrated that a psychodynamic interpretation does not necessarily have to be voiced and presented to children. Instead, it can be enacted and experienced. I never told Lina how I interpreted her actions (and it would have likely hurt our relationship had I done so), and I still have no way to validate my takes on the formation of 
her actions and agency, such as the link between her relationship with the father and her hostility towards me. However, my own actions were informed by these interpretations and they affected our day-to-day encounters with Lina as well as our broader relationship. And finally, a psychodynamic interpretation rests on an introspective analysis of one's own emotional experience (Proudfoot 2015). However, this differs from what social research usually classifies as 'reflexivity'. Here I concur with Mary Thomas's (2014) critique who suggests that 'putting a term like reflexivity to use means acknowledging the fantasy of full knowledge, both of the self (researcher) and of the other (researched)' (p.201).

Psychodynamic approaches are not the only theories that elucidate children's hostility not necessarily as an individual response to specific events in a particular relationship but rather see it as a legitimate expression of agency that can signal elements of wider social geographies and ontological security. The feminist literature on anger as a form of resistance reaches a similar conclusion through different means (Lorde 1986; Ahmed, 2004; Duffy 2017). What needs to be kept in mind is that although children's hostility (and anger or violence) might be difficult for the researcher to cope with at that particular moment due to its immediate presence and discomforting nature, it is vital to recognise that children's antagonism can very well be a sign of broader issues, relationships and social positioning outside the relationship with the researcher. Echoing Rachel Rosen's (2015) analysis of children's scream and Jouni Häkli and Kirsi Kallio's (2014) notes on children's political agency presented earlier, fixating on meanings and reasons behind children's hostility and on ascribing them a logic that conforms with adult systems of morality might very well downplay the significance of such acts as elements of children's embodied agency and how they matter (rather than what they mean) to children themselves.

I have argued that as a legitimate form of children's political agency, children's hostility should not be an obstacle to children's right to participation in research. However, as the story with Lina illustrates, addressing, understanding, responding to, and coping with children's hostility might requires a broader collaborative frame well beyond the individual relationship with the particular child. To interpret hostility might require information that will not be necessarily available from within that relationship, and the researchers must instead engage with others present in children's lives (in my case other children from the neighbourhood and adult practitioners). The interpretation of Lina's familial geographies incorporated a range of knowledges from other actors as well as rich ethnographic data, and a psychodynamic approach might be best used within a collaborative mode of research. Further, to cope with hostility might require complex emotional work on the part of the researcher that might need to be facilitated by experienced supervisors, and it might require an ongoing reflection not only on the incidents in the fieldwork but also on one's emotional response. Subsequently, this poses the question whether the most challenging encounters of hostility with children should not be examined in the light of researcher's own transferences and defence mechanisms. A psychodynamic approach (in contrast with the idea of research reflexivity) asserts that there are limits to individual introspection (Thomas 2014) and that attending to one's own emotional material can be best facilitated via help from trained professionals. In that respect, I suggest that the notion of research participation and collaboration then should be expanded beyond the space of research itself and draw more mindfully on the contribution to interpretations and knowledge production that people who are not necessarily involved in fieldwork activities or data analysis themselves can provide. In the story presented in this paper, I heavily drew on inputs from a professional supervisor (with clinical training) who was in no way involved in the research process as such, but whose reflection on my relationship with Lina helped shape not just the knowledge I produced within that research but also the course of the research itself. 
In conclusion, and in line with a wider body of literature on work with children (Holt 2004; Komulainen 2007; Woodyer 2008; Spyrou 2011; in addition to that discussed in more detail in the earlier part of the paper), this paper reiterates that there are limits to children's voice - what children can say, what they want to say, and how they can say it. Psychodynamic approaches are not mechanistic ways of making claims about children without their involvement, and they do not reduce children into passive objects of inquiry. It is the voice, language and spoken dialogue that are problematised, not the question of children's agency. Interpretations are generated through engagements with sources of many kinds, including words, observations and emotional reflections with a number of social actors present and relevant to children's lives. Then, even if those interpretations are not necessarily voiced - because they cannot be, or because the children refuse to engage with them - they are still placed back into iterative practices, relationships and embodied intersubjective dynamics with the children. To step away from voice is not a way of silencing children's perspectives, rather a decision to respect their right to be silent and antagonistic, and yet still maintain the right to participate in research. 
Adler, A. (1956a) Striving for superiority. In: Ansbacher, H.L., Ansbacher, R.R. (Eds) The Individual Psychology of Alfred Adler: A Systematic Presentation in Selection from his Writings, 101-125.

Adler, A. (1956b) Understanding and treating the problem child. In: Ansbacher, H.L., Ansbacher, R.R. (Eds) The Individual Psychology of Alfred Adler: A Systematic Presentation in Selection from his Writings, 384-410.

Adler, A. (2004/1928) The psychology of power. In: Stein, H.T. (Ed.) The Collected Clinical Works of Adler Adler, Vol. 6. Journal Articles 1927-1931: Structure \& Unity of Neurosis; Reason Feeling \& Emotion; Dream Theory. The Classical Adlerian Translation Project, Bellingham.

Adler, A. (2009/1927) Understanding Life: An Introduction To The Psychology Of Alfred Adler. A Oneworld Book, Oxford.

Adler, A. (2010/1932) What Life Should Mean to You. Martino Fine Books, Ealstford.

Ahmed, S. (2004) The Cultural Politics of Emotion. Edinburgh University Press, Edinburgh.

Aufseeser, D. (2018) Challenging conceptions of young people as urban blight: Street children and youth's ambiguous relationship with urban revitalization in Lima, Peru. Environment and Planning A: Economy and Space, 50(2), 310-326.

Bartos, Ann (2012) Children caring for their worlds: The politics of care and childhood. Political Geography 31(3), 157-166

Birch, J., Parnell, R., Patsarika, M., Šorn, M. (2017) Participating together: dialogic space for children and architects in the design process. Children's Geographies 15(2), 224-236.

Blazek, M., Smith, F.M., Lemešová, M., Hricová, P. (2015) Ethics of care across professional and everyday positionalities: The (un)expected impacts of participatory video with young female carers in Slovakia. Geoforum, 61, 45-55.

Bonaminio, V. (2007) The virtues of Anna Freud. In: Caldwell, L. (Ed.) Winnicott and the Psychoanalytic Tradition. Karnac, London, 97-111.

Bosco, F.J., Joassart-Marceli, P. (2015) Participatory planning and children's emotional labor in the production of urban nature. Emotion, Space and Society 16, 30-40.

Clark, A.J. (1998) Defense Mechanisms in the Counselling Process. Sage, London.

Couch, A. S. (1995). Anna Freud's adult psychoanalytic technique: A defence of classical analysis. The International Journal of Psychoanalysis, 76(1), 153-171.

Dreikurs, R. (1968) Psychology in the Classroom: A Manual for Teachers. Harper \& Row, New York.

Dreikurs, R., Stolz, V. (1987) Children: The Challenge. Dutton, New York.

Dreikurs, R. (1997/1972) Holistic medicine, Journal of Individual Psychology 53(2), 127-205.

Duffy, D.N. (2017) Time to look in/at anger: considerations on the position and policing of young people's anger. Journal of Youth Studies, 20(1), 1-15.

Einarsdóttir, E. (2007) Research with children: methodological and ethical challenges. European Early Childhood Education Research Journal, 15(2), 197-211. 
Elwood, S., Mitchell, K. (2012) Mapping children's politics: spatial stories, dialogic relations and political formation. Geografiska Annaler: Series B Human Geography, 94(1), 1-15.

Fay, F. (2018) The impact of the school space on research methodology, child participation and safety: views from children in Zanzibar. Children's Geographies 16(4), 405-417.

Fenichel, O. (1996/1946) The Psychoanalytic Theory of Neurosis. Routledge, London.

Fredrickson, J. (1999) Psychodynamic Psychotherapy: Learning to Listen from Multiple Perspectives. Routledge, New York.

Freud, A. (1951) Observations on child development. The Psychoanalytic Study of the Child 6(1), 1830.

Freud, A. (1974/1927) Introduction to the technique of child analysis. In: The Writings of Anna Freud Vol. 1. International Universities Press, New York.

Freud, A. (2018/1965) Normality and Pathology in Childhood: Assessments of Development. Routledge, New York.

Freud, A. (1992/1936) The Ego and the Mechanisms of Defence. Routledge, London.

Freud, S. (1955/1909) Analysis of a phobia in a five-year-old boy. In: Strachey, J. (Ed.) Standard Edition of the Complete Psychological Works of Sigmund Freud, Volume X. The Hogarth Press, London.

Freud, S. (1958/1914). Remembering, repeating, working-through (Further recommendations on the technique of psycho-analysis II). In: James Strachey (Ed.) Standard Edition of the Complete Psychological Works of Sigmund Freud, Volume XII. The Hogarth Press, London.

Freud, S. (1991/1923) The Ego and the Id. In: Freud, A. (Ed.) The Essentials of Psycho-Analysis: The Definitive Collection of Sigmund Freud's Writings. Penguin Books, London.

Gallagher, M. (2008) 'Power is not an evil': rethinking power in participatory methods. Children's Geographies 6(2), 137-150.

Hadfield-Hill, Horton, J. (2014) Children's experiences of participating in research: emotional moments together? Children's Geographies 12(2), 135-153.

Hall, S.M. (2011) Exploring the 'ethical everyday': an ethnography of the ethics of family consumption. Geoforum, 42(6), 627-637.

Harrowell, E., Davies, T., Disney, T. (2018) Making space for failure in geographic research. The Professional Geographer, 70(2), 230-238.

Häkli, J., Kallio, K.P. (2014) Subject, action and polis: theorizing political agency. Progress in Human Geography, 38(2), 181-200.

Harker, C., Hörschelmann, K., Skelton, T. (Eds) (2017 Conflict, Violence and Peace, Geographies of Children and Young People 11. Springer, New York.

Holt, L. (2004) The 'voices' of children: de-centring empowering research relations. Children's Geographies 2(1), 13-27.

Holt, L. (2013) Exploring the emergence of the subject in power: infant geographies. Environment and Planning D: Society and Space, 31(4), 645-663. 
Holt, L. (2017) Food, feeding and the material everyday geographies of infants: possibilities and potentials. Social and Cultural Geography, 18(4), 487-504.

Horton, J. (2008) A 'sense of failure'? Everydayness and research ethics. Children's Geographies 6(4), 363-383.

Horton, J., Kraftl, P. (2006) What else? some more ways of thinking and doing 'Children's Geographies'. Children's Geographies, 4(1), 69-95.

Kallio, K.P. (2007) Performative bodies, tactical agents and political selves: rethinking the political geographies of childhood, Space and Polity, 11(2), 121-136.

Kallio, K.P. (2012) Desubjugating childhoods by listening to the child's voice and childhoods at play. ACME: An International Journal for Critical Geographies, 11(1), 81-109.

Kallio, K.P., Häkli, J. (2011) Are there politics in childhood? Space and Polity, 15(1), 21-34.

Kallio, K.P., Thomas, M.E. (2019) Editorial: Intergenerational encounters, intersubjective age relations. Emotion, Space and Society, 32, 100575.

Karlsson, S. (2018) 'Do you know what we do when we want to play?' Children's hidden politics of resistance and struggle for play in a Swedish asylum centre. Childhood, 25(3), 311-324.

Kina, V.J. (2012) What we say and what we do: reflexivity, emotions and power in children and young people's participation. Children's Geographies, 10(2), 201-218.

Klocker, N. (2015) Participatory action research: The distress of (not) making a difference. Emotion, Space and Society 17, 37-44.

Komulainen, S. (2007) The ambiguity of the child's 'voice' in social research. Childhood, 14(1), 11-28.

Kraftl, P. (2013) Beyond 'voice', beyond 'agency', beyond 'politics'? Hybrid childhoods and some critical reflections on children's emotional geographies. Emotion, Space and Society, 9, 13-23.

Kraftl, P. (2020) After Childhood: Re-Thinking Environment, Materiality and Media in Children's Lives. Routledge, London.

Lorde, A. (1984) The uses of anger: women responding to racism. In: Lorde, A., Sister Outsider: Essays and Speeches. The Crossing Press, New York.

Nolas, S.-M. (2011) Reflections on the enactment of children's participation rights through research: Between transactional and relational spaces. Children and Youth Services Review, 33(7), 1196-1202.

Pells, K. (2012) 'Rights are everything we don't have': Clashing conceptions of vulnerability and agency in the daily lives of Rwandan children and youth. Children's Geographies 10(4), 427-440.

Pinkney, S. (2011) Participation and emotion: troubling encounters between children and social welfare professionals. Children \& Society, 25(1), 37-46

Poretti, M. (2019) Rights, participatory spaces and the daily fabric of children and young people's voices in Switzerland. Children's Geographies 17(4), 467-479.

Powell, M.A., Graham, A., McArthur, M., Moore, T., Chalmers, J., Taplin, S. (2019) Children's participation in research on sensitive topics: addressing concerns of decision-makers. Children's Geographies, early view. 
Powell, M.A., Smith, A.B. (2009) Children's participation rights in research. Childhood, 16(1), 124142.

Proctor, L. (2013) Exploring the role of emotional reflexivity in research with children. Emotion, Space and Society, 9, 80-88.

Proudfoot, J. (2015) Anxiety and phantasy in the field: the position of the unconscious in ethnographic research. Environment and Planning D: Society and Space, 33(6), 1135-1152.

Rautio, P. (2013) Children who carry stones in their pockets: on autotelic material practices in everyday life. Children's Geographies, 11(4), 394-408.

Rosen, R. (2015) 'The scream': Meanings and excesses in early childhood settings. Childhood, 22(1), 39-52.

Skovdal, M., Evans, R. (2017) The emergence of an ethic of care in rural Kenyan schools? Perspectives of teachers and orphaned and vulnerable pupils. Children's Geographies 15(2), 160-176.

Spyrou, S. (2011) The limits of children's voices: From authenticity to critical, reflexive representation. Childhood, 18(2), 151-165.

Thomas, M.E. (2014) When 1+1 does not equal 2: childhood, sexuality and Laplanche's enigmatic signifier. In: Kingsbury, P. and Pile, S. (Eds) Psychoanalytic Geographies. Ashgate, Farnham.

Thomas, M.E. (2019) "Y'all trying to make a mockery out of me." The confined sexualities of girls in a US juvenile detention facility. Emotion, Space and Society, 32, 100533.

van Blerk, L. and van Blerk, D. (2015) Biographical interviews as emotional encounters in street youth's lives: the role of research in facilitating therapeutic intervention. In: Blazek, M. and Kraftl, P. (Eds) Children's Emotions in Policy and Practice: Mapping and Making Spaces of Childhood. Palgrave MacMillan, London.

Warming, H. (2019) Messing with the emotions of the other exploring ambiguous youth-adult relations in a residential care institution. Emotion, Space and Society 32, 100512.

Woodyer, T. (2008) The body as research tool: embodied practice and children's geographies. Children's Geographies 6(4), 349-362. 